\title{
Implementasi Aplikasi JobSheet Mengunakan Bootstrap Studi Kasus PT XYZ
}

\author{
Arfan Sansprayada \\ Program Studi Sistem Informasi Kampus Kota Bogor \\ Universitas Bina Sarana Informatika \\ E-mail : arfan.anp@bsi.ac.id
}

\begin{abstract}
Abstraksi-Kebutuhan pengembangan sistem informasi dalam suatu perusahaan merupakan syarat dasar yang wajib harus dipenuhi oleh tiap perusahaan agar dapat menjalankan proses bisnis nya dengan baik. Hal ini yang menjadi kunci dasar dalam suatu perusahaan agar dapat memberikan hasil yang maksimal untuk mencari profit atau keuntungan yang sebanyak banyaknya. Pengembangan Aplikasi atau kebutuhan dalam aplikasi juga memberikan kecepatan terhadap karyawan untuk melakukan aktivitasnya bekerja secara baik dan maksimal. Perkembangan zaman menuntut untuk perusahaan harus dapat produktif dan mempunyai inovasi agar roda bisnis perusahaan dapat berjalan dengan baik. Hal ini didasari oleh perkembangan teknologi yang sangat begitu cepat sehingga membutuhkan keahlian khusus dalam penerapannya. Penelitian ini diharapkan dapat membantu beberapa permasalahan yang ada pada suatu perusahaan. Dimana penerapannya dapat mempermudah bagi karyawan dalam melakukan tugas dan peran masing masing agar dapat memaksimalkan potensi yang ada. Bagi perusahaan, penerapan aplikasi ini dapat mengakomodir roda bisnis perusahaan sehingga dapat terdokumentasinya dengan baik dan benar.
\end{abstract}

\section{Kata Kunci : Sistem, Informasi, Aplikasi}

\section{PENDAHULUAN}

Perkembangan zaman menuntut bagi setiap perusahaan agar dapat membuat inovasi-inovasi terbaik supaya dapat menjalankan proses bisnisnya secara baik dan benar. Hal ini yang harus dilakukan setiap perusahaan sehingga setiap perusahaan dapat bersaing secara baik sesuai dengan perkembangan zaman. Dari segi proses kebutuhan, penerapan aplikasi merupakan syarat mutlak bagi perusahaan agar dapat memberikan pelayanan terbaik kepada customer. Pelayanan ini dapat terpenuhi bila kecepatan kerja pada karyawan diperhatikan.

Memberikan pelayanan terbaik kepada customer atau pelanggan merupakan syarat mutlak yang wajib dipenuhi oleh perusahaan. Pelayanan tersebut memberikan dampak yang positif bila setiap karyawan dalam perusahaan memberikan pelayanan terbaik terhadap setiap pelanggan.

Performa booking merupakan proses bisnis yang dilakukan pada perusahaan sebagai langkah awal dalam proses proses yang lainnya. Hal ini menjadi syarat dasar memberikan respon yang baik terhadap customer agar dapat menjalankan proses bisnis lainnya.

Dengan memanfaatkan perkembangan teknologi yang ada sekarang ini diharapkan akan memberikan dampak yang positif terhadap perusahaan khususnya dalam penerapan aplikasi performa booking yang mana memberikan kecepatan karyawan dalam bekerja secara maksimal sehingga dampak yang terasa bagi perusahaan adalah memberikan profit atau keuntungan pada perusahaan dan dapat menjalankan proses bisnis secara baik dan benar

\section{METODE PENELITIAN}

\subsection{Pengertian Sistem Informasi}

Sistem informasi mempunyai peran penting dalam kinerja sebuah organisasi. Sistem informasi memberikan banyak keuntungan, dari tugas yang simple seperti proses transaksi pada level operasional sampai ke tugas yang sulit seperti membuat keputusan penting dan kompetitif pada tingkat strategis organisasi.

\subsection{PERMODELAN Sistem BERBASIS OBJEK (PSBO)}

Dalam (Rosa \& Shalahuddin, 2016), Metodologi berorientasi objek adalah suatu strategi pembangunan perangkat lunak sebagai kumpulan objek yang berisi data dan operasi yang diberlakukan terhadapnya. Metodologi berorientasi objek merupakan suatu cara bagaimana sistem perangkat lunak dibangun melalui pendekatan objek secara sistematis. Object Oriented Programming (OOP) memfokuskan objek dimana sistem nantinya dibangun akan dibagi ke dalam beberapa objek yang ada di dalamya.

\subsection{PROSES BISNIS}

Proses bisnis adalah suatu kumpulan aktivitas atau pekerjaan terstruktur yang saling terkait untuk menyelesaikan suatu masalah tertentu atau yang menghasilkan produk atau layanan (demi meraih tujuan tertentu). (Puspitasari, 2015) menerangkan bahwa pengamatan terhadap analisa sistem berjalan dilakukan untuk mengetahui sistem yang saat ini sedang berjalan serta mengenali kebutuhan- kebutuhan pengguna serta menemukan kendala- kendala yang ada pada sistem yang berjalan dan memberikan alternatif pemecahan masalah. 


\subsection{Unified Modelling Languange (UML)}

Unified Modelling Languange (UML) yang berarti bahasa permodelan standar. Dalam (Muslihudin \& Oktafianto, 2016), Chonoles mengatakan sebagai bahasa, berarti UML memiliki sintaks dan semantik. Pembuatan model menggunakan konsep UML ada aturan - aturan yang harus diikuti. Bagaimana elemen pada model - model UML berhubungan satu dengan yang lainnya harus mengikuti standar yang ada. UML bukan sekedar diagram, tetapi juga menceritakan konteksnya.

(Muslihudin \& Oktafianto, 2016) juga menjelaskan UML diaplikasikan untuk maksud tertentu, biasanya antara lain :

a. Merancang perangkat lunak.Sarana komunikasi antara perangkat lunak dan proses bisnis.

b. Menjabarkan sistem secara rinci untuk analisis dan mencari apa yang diperlukan sistem.

c. Mendokumentasi sistem yang ada, proses-proses dan organisasinya.

\subsection{User Interface}

Menurut (Syahputra \& Amin, 2016), "Desain User Interface atau biasa disebut UI adalah faktor yang sangat penting untuk membuat aplikasi. User biasanya lebih suka berinteraksi dengan antarmuka sesederhana mungkin.".

User Interface berfungsi untuk :

a. Menghubungkan antara pengguna dengan sistem operasi sehingga komputer dapat digunakan.

b. Menampilkan penjelasan sistem dan memberikan panduan pemakain sistem secara menyeluruh step by step sehingga user mengerti apa yang akan dilakukan terhadap suatu system.

c. Kemudahan dalam memakai / menjalankan sistem, interaktif, komunikatif.

Perancangan antarmuka memfokuskan pada tiga area yaitu rancangan antarmuka antara modul-modul perangkat lunak, rancangan antarmuka antara perangkat lunak dengan entitas eksternal dan rancangan antarmuka antara perangkat lunak dengan pengguna perangkat lunak (manusia dengan komputer)

\section{HASIL DAN PEMBAHASAN}

\subsection{Tinjauan Perusahaan}

PT XYZ merupakan salah satu perusahaan yang bergerak dibidang MKL. Yaitu perusahaan yang membidangi jasa pelayaran eksport dan import, trucking serta dokumentasi kebutuhan akan eksport dan import yang biasa disebut custom clearance. Perusahaan yang mempunyai karyawan kurang lebih dari 100 orang ini bekerja sama dengan beberapa agen diseluruh dunia baik dari benua asia, eropa ataupun afrika. Kecepatan dan memberikan pelayanan terbaik merupakan visi dan misi dari perusahaan ini.

3.2 Proses Bisnis Sistem Berjalan a. Order Dari Customer/Pelanggan

Customer akan melakukan order baik berupa email atau telp kepada karyawan dimana menanyakan jasa pengiriman barang dalam bentuk peti kemas baik ke dalam atau luar negeri dengan menggunakan pelayaran atau shipping line.

b. Kesepakatan Harga

Setelah menanyakan informasi masalah pengiriman barang, maka customer dan management akan mensepakati masalah harga dari biaya pengiriman jasa barang tersebut. Harga meliputi dari banyak hal. Mulai dari biaya peti kemas, biaya beacukai, dll.

c. Pembuatan Job Sheet

Karyawan akan melakukan penginputan JobSheet setelah order yang disepakati baik dari sisi customer dan perusahaan

3.3 Permasalahan Pokok

a. Penginputan Harga Jual dan Harga Beli dan Data Kontainer yang masih bersifat manual yang diformulasikan dalam bentuk Microsoft excel.

b. Penginputan Jobsheet yang masih dalam bentuk form kosong Job Sheet.

c. Penginputan Request giro dalam berbentuk manual berbentuk form kosong request giro.

\subsection{Pemecahan Masalah}

Dengan adanya aplikasi Job Sheet pada perusahaan ini diharapkan dapat memecahkan masalah diantaranya adalah

a. Memudahkan pegawai untuk melakukan penginputan Harga Jual, Harga Beli, Data Kontainer serta Penginputan JobSheet secara cepat dan tepat dan tidak lagi adanya data yang bertumpuk dan berulang.

b. Dengan adanya aplikasi ini diharapkan proses request pengaprovean giro dapat dilakukan secara cepat ke pihak divisi accounting dimana sudah diterapkan nya menu request giro dalam aplikasi tersebut yang langsung terhubung ke divisi finance.

\subsection{Analisa Kebutuhan}

Berdasarkan proses bisnis berjalan maka tahapan analisa kebutuhan diantaranya adalah sebagai berikut :

A. Karyawan Mengakses Login
a. Menginput Username
b. Menginput Password

B. Karyawan Mengakses Menu Utama
a. Mengakses Dashboard
b. Mengakses Master Company
c. Mengakses Master Location
d. Mengakses Master Data
e. Mengakses Master Company Data
f. Mengakses Menu Trucking
g. Mengakses Accounting

C. Karyawan Mengakses Master Company

a. Mengakses Master data Customer 

b. Mengakses RC Vendor
c. Mengakses Trucking
d. Mengakases Trucking Internal

D. Karyawan Mengakses Master Location
a. Mengakses Container Depo
b. Mengakses Discharge Location
c. Mengkases Sea Port
d. Mengakses Stuffing Location

E. Karyawan Mengakses Master Data
a. Mengakses Container Type
b. Mengakses Sales

F. Karyawan Mengakses Master Company Data
a. Mengakses Company Address
b. Mengakses Company Name
c. Mengakses Company Type

G. Karyawan Mengakses Menu Trucking
a. Mengakses Daftar Harga Beli
b. Mengakses Daftar Harga Jual
c. Mengakses Data Kontainer
d. Mengakses Job Sheet
e. Mengakses Shipping Instruction
f. Mengakses Trucking Search

H. Karyawan Mengakses Accounting

a. Mengakses Request Giro

3.6 UseCase Diagram Menu Utama

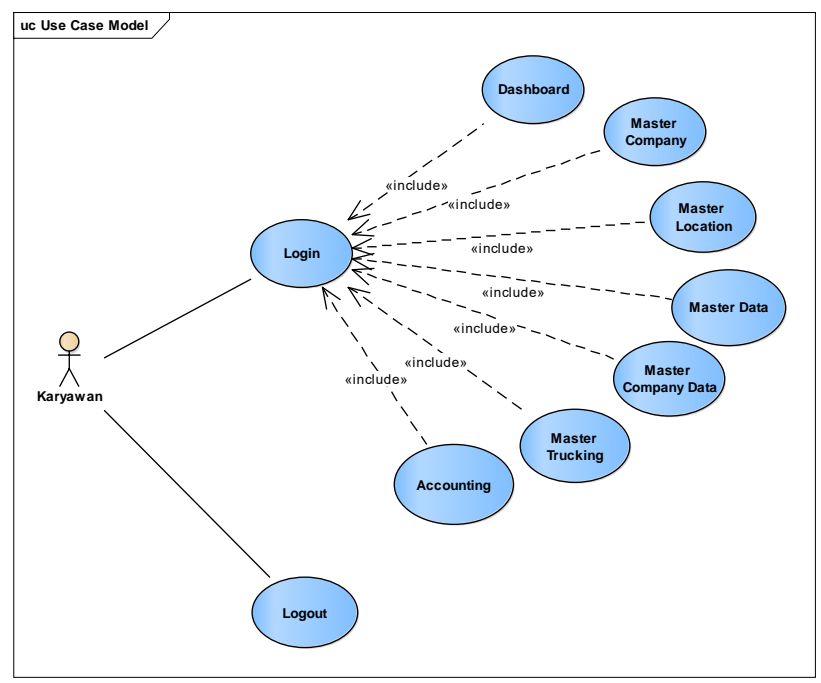

Gambar III.1 Use Case Diagram

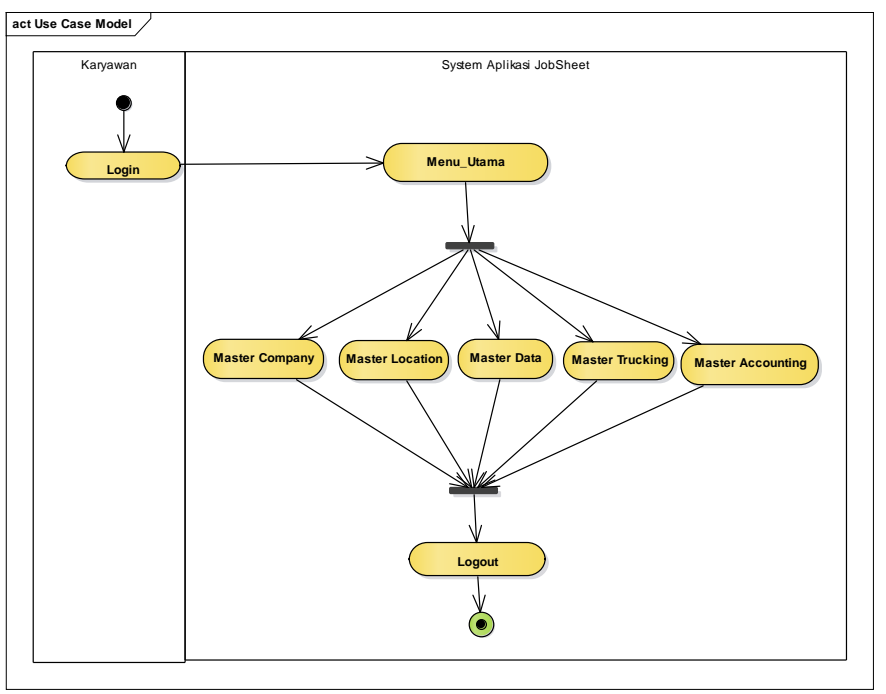

Gambar III.2 Activity Diagram

\subsection{Sequence Diagram}

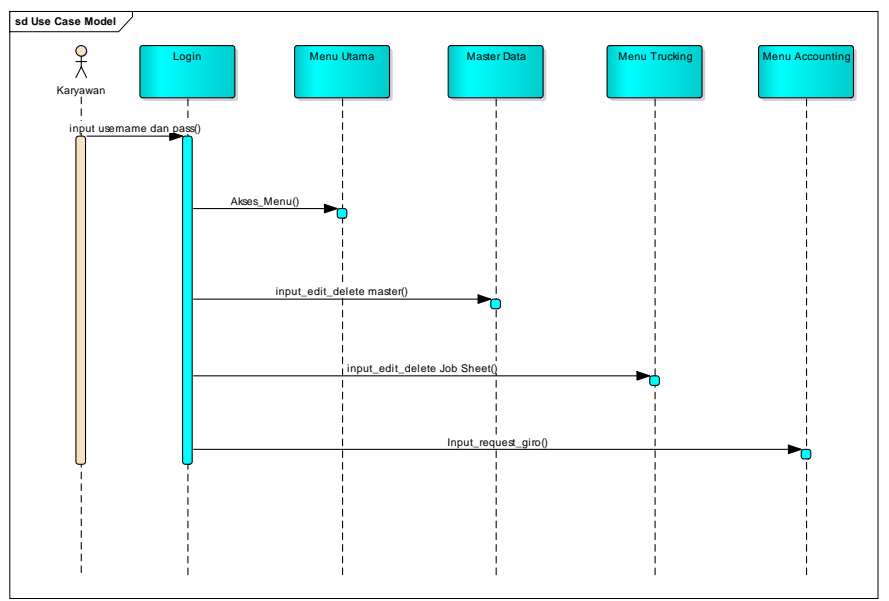

Gambar III.3 Sequence Diagram

3.9 User Interface Daftar Harga Beli

3.7 Activity Diagram Menu Utama 


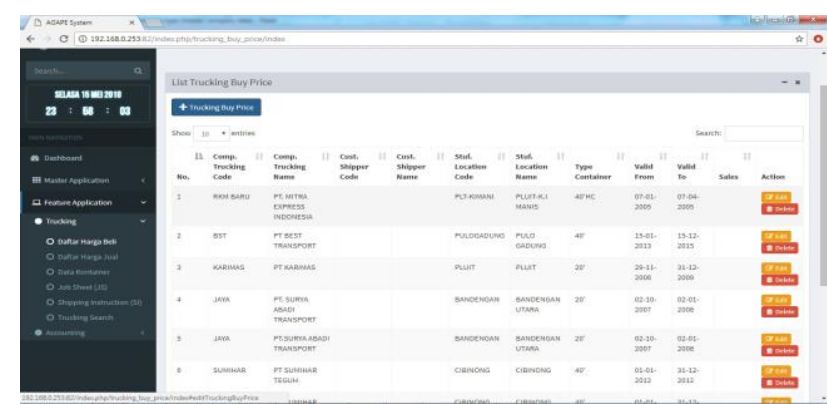

Gambar III.4 User Interface Daftar Harga Beli

3.10 User Interface Daftar Harga Jual

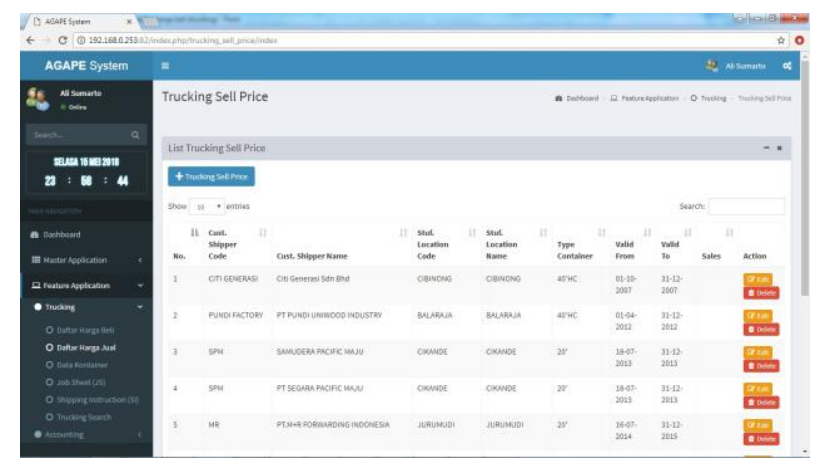

Gambar III.5 User Interface Daftar Harga Jual

3.11. User Interface Data Kontainer

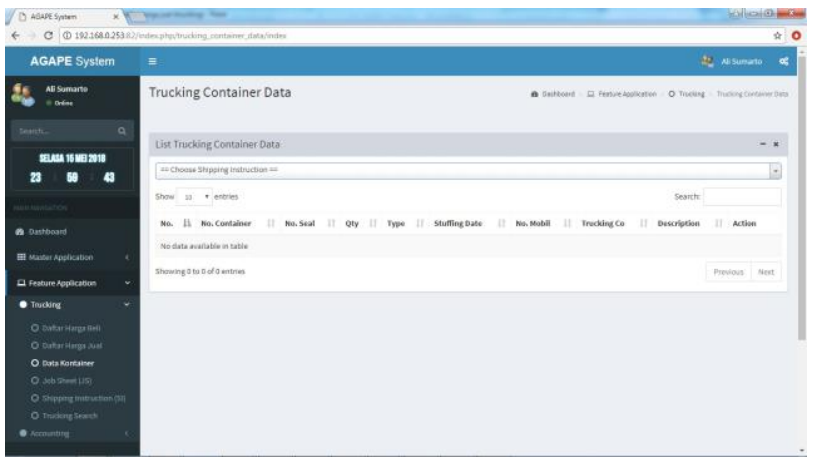

Gambar III.6 User Interface Data Kontainer

3.12. User Interface Job Sheet

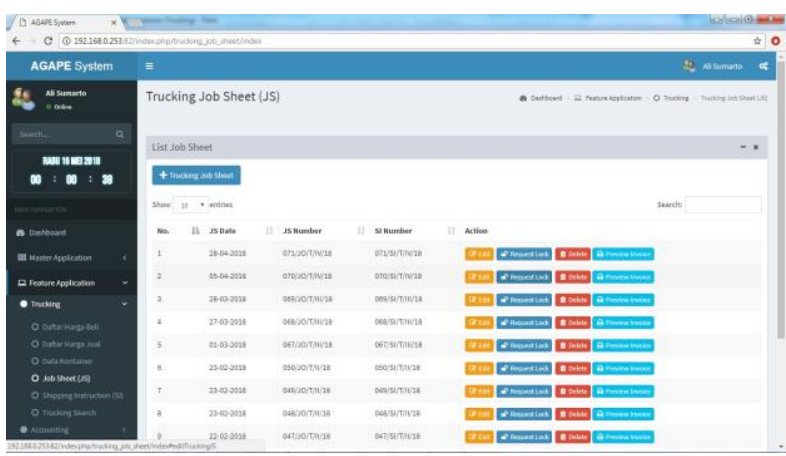

Gambar III.7 User Interface Job Sheet

3.13 User Interface Shipping Instruction

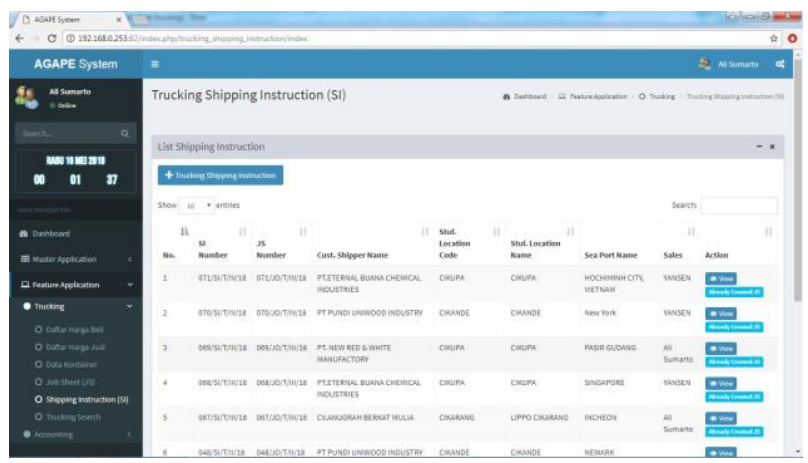

Gambar III.8 User Interface Shipping Instruction

\subsection{User Interface Trucking Search}

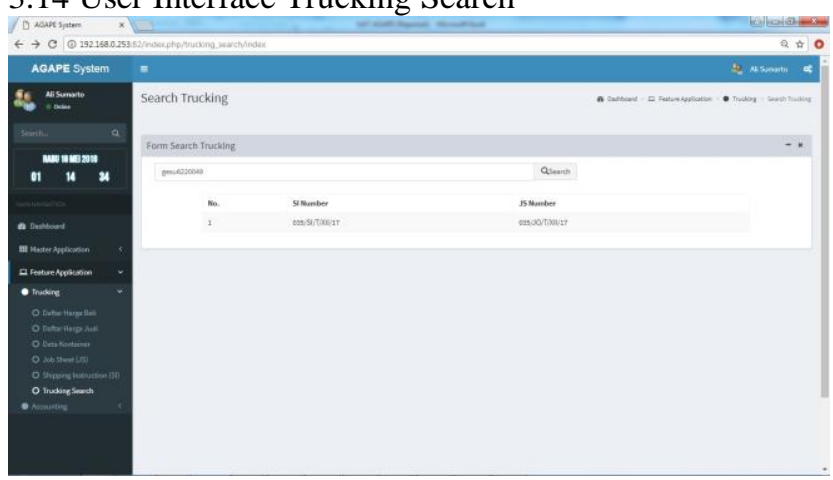

Gambar III.9 User Interface Trucking Search

3.15 User Interface Request Giro 


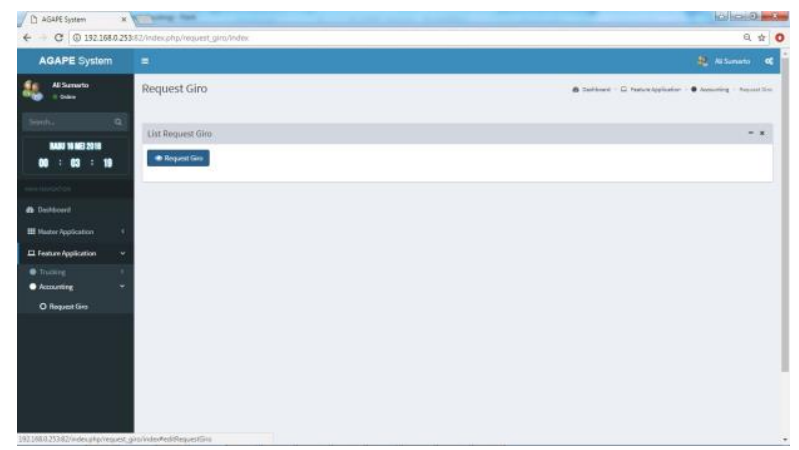

Gambar III.10 User Interface Giro

\section{KESIMPULAN}

Permasalahan pokok sistem tersebut, penulis menarik beberapa kesimpulan diantaranya adalah :

1. Pembuatan JobSheet yang masih berbasis manual dengan berbentuk form sederhana dan diformulasikan kedalam Microsoft excel agar dapat terdokumentasi. Hal ini yang menyebabkan data banyak yang berulang dan tidak terdokumentasi dengan baik. Dari sisi kecepatan sangat lama dirasakan untuk satu kali pemrosesan pembuatan JobSheet karena dibutuhkan pencocokan data terlebih dahulu baik dari harga jual dan harga belinya.

2. Dengan dirancangnya implementasi Aplikasi JobSheet ini diharapkan mengurangi permasalahan permasalahan yang ada pada permasalahan tsb sehingga memberikan kemudahan bagi karyawan dalam menjalankan tugas dan peran nya masing masing sedangkan dari sisi perusahaan dapat menjalankan proses bisnis secara maksimal dan mempunyai pelayanan terbaik yang dibutuhkan customer atau pelanggan.

Perancangan sistem informasi ini tidak akan berjalan dengan baik apabila tidak dibarengi dengan kedispilinan dan tanggung jawab dari semua pihak dalam perusahaan. Oleh karena itu untuk memperlancar fungsi dan peran masing masing di perusahaan penulis ingin memberikan saran diantaranya adalah :

1. Adanya training berkala terhadap karyawan tentang fitur fitur yang ada pada aplikasi tersebut. Penerapan training diharapkan memberikan pengetahuan serta alur yang baik terhadap aplikasi tersebut.

2. Diperlukannya maintenance atau perawatan dari sisi software ataupun hardware agar kelangsungan proses bisnis tetap berjalan dengan baik tanpa ada kendala sedikitpun.

3. Perkembangan atau update aplikasi bila memungkinkan sesuai dengan kebutuhan user di masa yang akan mendatang.

\section{DAFTAR PUSTAKA}

Anggraeni, E. Y., \& Irviani, R. (2017). Pengantar Sistem Informasi. (E. Risanto, Ed.).Yogyakarta: Penerbit

Andi.Bakhri, S. (2015). Rancang Bangun Sistem Informasi Penjualan Sembako Menggunakan Metode Waterfall, 3(1), 70-82.

Hery. (2012). Pengantar Akuntansi 1. Jakarta: Fakultas Ekonomi Universitas Indonesia.

Muslihudin, M., \& Oktafianto. (2016). Analisis dan Perancangan Sistem Informasi Menggunakan Model Terstruktur dan UML. (A. Pramesta, Ed.). Yogyakarta: Penerbit Andi.

Puspitasari, D. (2015). Rancang Bangun Sistem Informasi Koperasi Simpan Pinjam Karyawan Berbasis Web. Seminar Nasional Ilmu Pengetahuan Dan Teknologi Komputer, XI(2), 186-INF.196.

Rahmawati, M. (2015). Peran Aplikasi Komputer Berbasis Akuntansi untuk Badan Usaha Dalam Persfektif Sistem Informasi, XIII(2), 172-183.

Ramanda, K., Rusman, A., \& Agustin, R. (2017). Rancang Bangun Sistem Informasi Service Center Pada PT . Catur Sukses Internasional Jakarta, 7(2), 1-5.

Rosa, A. S., \& Shalahuddin, M. (2016). Rekayasa Perangkat Lunak Terstruktur dan Berbasis (Puspitasari, 2015)Objek. Bandung: Informatika.

Syahputra, R., \& Amin, S. (2016). IOS Visual Programming. Yogyakarta: Mediakom.

\section{BIODATA PENULIS}

Arfan Sansprayada. Jakarta 27 Oktober 1984. S1-Teknik Informatika Perbanas-Jakartan dan S2-Ilmu Komputer Stmik Nusa Mandiri-Jakarta. Saat ini aktif sebagai pengajar di Universitas Bina Sarana Informatika dan STIMIK Nusa Mandiri. 